\title{
PELATIHAN PEMBUATAN BROSS DENGAN BAHAN DASAR KAIN PERCA DESA CANGKRINGTURI KECAMATAN PRAMBON KABUPATEN SIDOARJO
}

\author{
Aristha Purwanthari ${ }^{1}$, Agustinus Obed ${ }^{2}$, Afia Wildani ${ }^{3}$, Arga Firmansyah ${ }^{4}$, Dewi Purnama Sari ${ }^{5}$ \\ ${ }^{1}$ Fakultas Ekonomi, Universitas PGRI Adi Buana Surabaya, \\ 2,3,4,5 Fakultas Keguruan Dan Ilmu Pendidikan, Universitas PGRI Adibuana Surabaya \\ Email: ${ }^{2}$ Augs_oi71@yahoo.com, ${ }^{4}$ argafirmansyah@mail.com
}

\begin{abstract}
Cain perca handicrafts are Crafts that memperpadukan between traditional and contemporary art. Perca handicraft is a combination of two sheets of cloth center in charge with the warming batting material from silicone. The top layer of handicrafts perca can consist of a combination or one of the patch work or application. The three layers of shaped sandwhich sewn with tailoring machine or hand (Delujur).Use of fabrics perca can be various forms but this time the use of fabrics perca only focused on bross. Bross is bross to scarf, so the committee invited only PKK mothers and women representatives from each RT. For the purpose of this activity is aimed to provide skills to the community so that later can increase their creativity and productivity to the community besides that can increase the level of community economic Turi Cangkring village when the handicrafts perca cloth can be in comersil. In the era of MEA economic competition tight enough so the requirement of qualified Human Resources improvements to compete with other countries. All the people who follow the training quite enthusiastic so that the implementation of the training the alleged price running well enough and smoothly. For almost two hours the people have been able to create bross from cain perca. As a result most people who participate are able to create bross beautiful and beautiful. Saw it should be village governments provide mentor for people who want to serve in the world of business sales bross. So that the proceeds from the sale of bross additional will gesture can earn money for their families.
\end{abstract}

Keyword: training, bross, patchwork.

\section{PENDAHULUAN}

Sebagian besar masyarakat sudah mengetahui apa itu kain perca, kain sisa potongan yang sudah tidak terpakai tersebut ternyata masih bisa dimanfaatkan. Bahkan ditangan - tangan kreatif, kain perca dapat disulap menjadi barang-barang kerajinan yang trendi dan tentunya bermanfaat.Membuat kerajinan kain perca, ternyata tidak serumit yang kita bayangkan, cukup sedikit ketelitian dan kreatifitas kita saja.

Kain perca merupakan sisa kain dari proses penjahitan. Sepintas kain sisa ini adalah kain yang tidak memiliki manfaat, tapi sebenarnya sisa kain ini dapat dimanfaatkan menjadi suatu produk yang berguna. Daripada terbuang menjadi sampah lebih baik digunakan sebagai barang yang lebih berguna. Kain perca ini dapat dimanfaatkan menjadi barang- barang kerajinan tangan seperti tas, sarung bantal, ataupun produk-produk yang lain.

Usaha ini bergerak dalam bidang industri rumah tangga, pada dasarnya didirikan bertujuan untuk mencari keuntungan serta untuk memenuhi kebutuhan atau permintaan konsumen akan suatu produk yang berkualitas dan bermutu. Sedangkan penciptaan kualitas dan mutu yang baik dengan biaya yang rendah adalah syarat utama jika menginginkan keuntungan yang terus meningkat.

Kerajinan kain perca merupakan salah satu kerajinan yang menjadi bagian dari dunia jahit-menjahit. Kerajinan ini dibuat dengan menggunakan bahan yang 
tergolong limbah, yaitu bermacammacam kain perca. Kain ini digunakan untuk membuat sebuah karya kerajinan yang indah dan bahkan memiliki nilai seni tinggi.

Caranya adalah dengan memotongmotong beragam kain sisa menjadi berbagai bentuk, kemudian menggabungkan potongan-potongan tersebut dengan menjahitnya kembali. Tentunya perpaduan warna dan pola kain juga harus diperhatikan agar bisa tercipta sebuah kerajinan perca yang indah.

Kerajinan kain perca saat ini sudah menjadi salah satu kerajinan yang paling dikagumi dan diminati oleh banyak orang Indonesia, bahkan juga di seluruh dunia. Awalnya kerajinan ini merupakan salah satu kerajinan tradisional. Namun, sekarang kerajinan ini malah menjadi salah satu tren baru di dunia kerajinan. Kain perca merupakan sisa kain dari proses penjahitan. Sepintas kain sisa ini adalah kain yang tidak memiliki manfaat, tapi sebenarnya sisa kain ini dapat dimanfaatkan menjadi suatu produk yang berguna. Daripada terbuang menjadi sampah lebih baik digunakan sebagai barang yang lebih berguna. Kain perca ini dapat dimanfaatkan menjadi barang-barang kerajinan tangan seperti tas, sarung bantal, ataupun produkproduk yang lain. (http://databermanfaat.blogspot.co.id/2014/0 6/berbagi-makalah-bertemakan-kainperca.html)

Kerajinan tersebut terbentuk adanya sentuhan-sentuhan kontemporer yang diberikan pada kreasi-kreasi baru yang tercipta. Sekarang, kita bisa menemukan kerajinan kain ini dalam beragam jenis kreasi serta pola yang indah dan bernilai seni tinggi seperti bed cover, taplak meja cantik, baju, tas, sajadah, hiasan dinding, dan lain sebagainya.

\begin{tabular}{lrr}
\multicolumn{1}{c}{ Menurut } & shofyiatun & $(2010)$ \\
kerajinan kain & perca & adalah \\
Seni Kerajinan & yangmemperpadukan \\
antara seni & tradisional & dan \\
kontemporer. Kerajinan Perca merupakan \\
gabungan dua lembar kain yang
\end{tabular}

tengahnya diisi dengan bahan penghangat batting dari silikon. Lapisan atas kerajinan perca bisa terdiri dari gabungan atau salah satu dari patch work atau aplikasi. Ketiga lapisan berbentuk sandwhich dijahit dengan jahitan mesin atau tangan (Delujur).

Apabila masyarakat desa Cangkring turi diberikan pelatihan untuk memanfaatkan kain perca sebagai kerajinan bross yang memiliki nilai jual maka secara tidak langsung desa Cangkring Turi dapat mendirikan UMKM bertujuan untuk memberikan keterampilan kepada masyarakat sehingga nantinya dapat meningkatkan kreatifitas dan produktivitas kepada masyrakat selain itu dapat meningkatkan tingkat ekonomi masyarakat desa Cangkring Turi pabila hasil kerajinan kain perca tersebut dapat di komersilkan. Menurut Kementrian Keuangan Berdasarkan Keputusan Menteri Keuangan Nomor 316/KMK 016/1994 tanggal 27 Juni 1994 bahwa Usaha Kecil sebagai perorangan/badan usaha yang telah melakukan kegiatan /usaha yang mempunyai penjualan/omset per tahun setinggi-tingginya Rp. 600.000.000 atau asset (aktiva ) setinggitingginya Rp.600.000.000 (diluar tanah dan bangunan yang ditempati ).

Contohnya Firma, CV, PT, dan Koperasi yakni dalam bentuk badan usaha. Sedangkan contoh dalam bentuk perorangan antara lain pengrajin industri rumah tangga, peternak, nelayan, pedagang barang dan jasa dan yang lainnya sedangkan menurut Rudjito (2010) bahwa Beliau mengemukakan bahwa Usaha Mikro Kecil dan Menengah adalah usaha yang memiliki peran yang penting dalam perekonomian Indonesia, baik ditinjau dari segi jumlah usaha maupuan dari segi penciptaan lapangan kerja, sedangkan Menurut Suryani (2014) pemanfaatan barang bekas menjadi suatu hal yang ekonomis adalah hal yang mudah tergantung dari pola pikir dan minat dari seseorang.

Dari paparan diatas maka diharapkan masyarakat desa Cangkring Turi dapat 
menghasilkan produk yang memiliki nilai jual dan seni.

Selain itu juga dapat memberikan keterampilan kepada Masyarakat desa Cangkring Turi sehingga nantinya bisa digunakan untuk penghasilan tambahan keluarganya.Pada ujungnya tingkat ekonomi masyarakat desa Cangkring Turi dapat meningkat.

\section{METODE PELAKSANAAN}

Kerajinan kain perca sebenarnya sudah cukup lama dikenal di Indonesia dan juga termasuk ke dalam kerajinan seni tradisional.Awalnya kerajinan perca di Indonesia kurang diminati. Karena pembuatannya yang berbahan dasar limbah perca, kerajinan ini menjadi dipandang sebelah mata.

Namun, seiring dengan semakin meningkatnya daya kreatifitas dan kualitas bahan yang digunakan oleh para pengrajin, saat ini kerajinan ini semakin populer. Ada banyak sekali orang yang ingin memiliki dan juga mempelajari seni kerajinan ini. Barang-barang hasil kerajinannya pun semakin beragam dan bernilai jual cukup tinggi.

Kerajinan kain ini juga menjadi salah satu kerajinan yang diminati para ibu rumah tangga dan remaja putri untuk dipelajari. Sudah banyak kelompokkelompok kreatif yang khusus mengerjakan berbagai kerajinan kain ini dan menjualnya.

Bahkan, tidak sedikit dari kelompokkelompok tersebut yang sukses menciptakan kerajinan berkualitas dan bernilai seni tinggi hingga dapat menembus pasar internasional. Jadi, kerajinan ini juga bisa menjadi peluang usaha yang menjanjikan bagi para ibu rumah tangga, remaja putri atau siapa saja yang memiliki bakat dan minat di bidang jahit-menjahit.

Jika Anda tertarik dengan dunia kreasi kerajinan kain perca, anda juga bisa belajar membuat dan menghasilkan karya yang tidak kalah berkualitas.Anda bisa mulai belajar dari teknik-teknik dasar terlebih dahulu dan kemudian mulai mengembangkan

kreasi setelah anda cukup mahir.

Untuk mempelajari kerajinan perca ini, Anda bisa belajar secara otodidak dengan membaca berbagai buku panduan yang bisa ditemukan di berbagai took buku, baik on line maupun offline. Selain itu, Anda juga bisa belajar langsung dari para pengrajin kain perca yang saat ini sudah cukup banyak yang membuka kursus kerajinan perca untuk umum.

Banyak orang yang tidak tahu bahwa kain perca sangat bermanfaat, terutama kain perca batik khususnya. Biasanya setelah sehelai kain selesai dijahit atau dibuat pakaian, sisanya akan terbuang sia-sia. Padahal sisa-sisa kain itu masih bisa dimanfaatkan menjadi bermacammacam kerajinan yang fungsional. Ada beberapa jenis kain perca batik yang masing-masing berbeda jenis bahan.Dua diantaranya yang paling banyak adalah jenis kain batik dari bahan katun dan sunwosh.

Kain perca batik bisa dimanfaatkan menjadi beberapa bentuk kerajinan yang fungsional dan bernilai jual, misalnya tas, Sandal, Taplak meja, Sprei, sarung bantal dan sarung guling, Tudung saji dan tutup gelas, Bros, Keset, Rok atau daster, dan lain-lain.

Memanfaatkan kain perca sebagai bahan baku utama pembuatan aneka kerajinan ternyata bisa menjadi salah satu peluang bisnis yang sangat menguntungkan. Dari kain sisa jahitan yang awalnya tidak bernilai, bisa dikreasikan menjadi berbagai macam produk kerajinan yang memiliki fungsi dan harga jual cukup tinggi.

Dengan memproduksi aneka macam produk kerajinan kain perca, tentunya Anda bisa membidik pangsa pasar yang cukup luas. Sebut saja produk kebutuhan rumah tangga seperti bed cover, sprei, keset, dan lain-lainbisa Anda pasarkan untuk kalangan ibu-ibu. Sedangkan untuk produk boneka, kotak pensil, tas, dan dompet handpone, bisa Anda tujukan 
untuk konsumen anak-anak maupun kaum remaja.

Untuk memulai bisnis kerajinan kain perca, ada beberapa persiapan yang harus Anda perhatikan :

1. Pertama-tama tentukan ide dan desain produk yang akan Anda produksi. Sesuaikan desain yang Anda buat dengan target pasar yang ingin Anda bidik. Contohnya saja desain warna-warni cerah untuk konsumen anak-anak dan remaja, sedangkan untuk konsumen ibu-ibu bisa memilih desain yang lebih simpel dengan warna yang lebih kalem.

2. Perluas pengetahuan dan kemampuan Anda dengan membaca buku-buku kreasi perca maupun searching model-model baru dari internet. Langkah ini cukup penting agar produk Anda tidak ketinggalan zaman.

3. Persiapkan peralatan dan perlengkapan yang dibutuhkan selama proses produksi berlangsung. Mulai dari mesin jahit, benang, jarum, gunting, dan lain sebagainya.

4. Jalin kerjasama dengan pemasok kain perca.

Bisa saja Anda mendapatkan kain perca dari tukang jahit di sekitar kota Anda, atau dari toko-toko kain yang memiliki sisa potongan kain cukup banyak. Bisnis kerajinan kain perca termasuk salah satu peluang usaha yang bisa dijalankan dengan modal kecil namun menjanjikan untung yang cukup besar bagi pelakunya. Bahan baku kain perca bisa Anda dapatkan dengan harga murah meriah dari para penjahit maupun pabrik konveksi yang ada di sekitar lokasi Anda. Bahkan bila Anda sudah menjalin hubungan baik dengan pelaku bisnis konveksi, pasokan potongan kain sisa bisa Anda dapatkan secara cumacuma alias gratisan dari rekanan bisnis Anda.

Kendala yang sering dihadapi para pelaku usaha yaitu tingkat persaingan produk yang semakin ketat. Saat ini sudah banyak pelaku bisnis yang memproduksi aneka macam barang daur ulang untuk merebut perhatian konsumen. Selain itu, terkadang bahan kain perca yang Anda dapatkan tidak semuanya berkualitas bagus. Hal ini membuat kualitas produk anda juga akan ikut menurun. Karenanya untuk menghindari resiko tersebut, sebelumnya lakukanlah penyortiran untuk memisahkan kain perca yang berkualitas bagus dan yang kurang berkualitas.

Dalam memasarkan produk kerajinan daur ulang, anda bisa menitipkan hasil kreasi yang telah dibuat ke beberapa kios souvenir maupun toko perabot rumah tangga yang ada di sekitar lokasi bisnis anda. Dengan strategi pemasaran tersebut, anda bisa menggunakan sistem konsinyasi (titip jual) maupun sistem jual putus kepada partner bisnis Anda.

Selanjutnya anda juga bisa memperluas pasar dengan mengikuti berbagai kegiatan pameran maupun bazar produk UKM yang diadakan pihak pemerintah maupun swasta.Melalui event seperti pameran dan bazar, anda bisa mengenalkan produk kerajinan daur ulang kain perca kepada masyarakat luas, sehingga peluang anda untuk mendapatkan pelanggan maupun partner kerja yang cukup potensial semakin terbuka lebar.

Strategi promosi juga bisa anda jalankan melalui jaringan internet. Sekarang ini peran media online bagi pemasaran produk sudah tidak perlu diragukan lagi, jadi anda bisa memanfaatkan kondisi tersebut dengan membuat website, blog, facebook, twitter, atau bergabung dengan forumforum diskusi via online untuk memperluas peluang pasar yang Anda miliki.

III. HASIL DAN PEMBAHASAN

\begin{tabular}{|c|c|c|c|}
\hline $\begin{array}{l}\mathbf{N} \\
\mathbf{O}\end{array}$ & $\begin{array}{c}\text { Mingg } \\
\text { u Ke- }\end{array}$ & $\begin{array}{c}\text { Hari/Tangg } \\
\text { al }\end{array}$ & Kegiatan \\
\hline $\mathbf{1}$ & $\begin{array}{l}\text { Mingg } \\
\text { u ke-1 } \\
\text { Mingg } \\
\text { u ke-2 }\end{array}$ & $\begin{array}{c}\text { Kamis, } 2 \\
\text { Februari } \\
2017\end{array}$ & $\begin{array}{c}\text { Kordinasi } \\
\text { dengan } \\
\text { RT/RW dan } \\
\text { PKK }\end{array}$ \\
\hline
\end{tabular}




\begin{tabular}{|c|c|c|}
\hline \multirow[t]{4}{*}{2} & $\begin{array}{c}\text { Sabtu, } 4 \\
\text { Februari } \\
2017\end{array}$ & $\begin{array}{c}\text { Rapat } \\
\text { anggota dan } \\
\text { panitia } \\
\text { pelatihan } \\
\text { pemanfaatan } \\
\text { kain perca }\end{array}$ \\
\hline & $\begin{array}{c}\text { Senin, } 6 \\
\text { Februari2017 }\end{array}$ & $\begin{array}{c}\text { Penyusunan } \\
\text { proposal } \\
\text { pelatihan } \\
\text { pemanfaatan } \\
\text { kain perca }\end{array}$ \\
\hline & $\begin{array}{l}\text { Minggu, } 12 \\
\text { Februari2017 }\end{array}$ & $\begin{array}{c}\text { Praktek } \\
\text { pelaitahan } \\
\text { pemanfaatan } \\
\text { kain perca di } \\
\text { Kediaman } \\
\text { Kepala } \\
\text { Dusun Turi } \\
\text { Desa } \\
\text { Cangkringtu } \\
\text { ri }\end{array}$ \\
\hline & $\begin{array}{c}\text { Selasa, } 14 \\
\text { Februari } \\
2017\end{array}$ & $\begin{array}{c}\text { Evaluasi } \\
\text { kegiatan } \\
\text { pelaitahan } \\
\text { pemanfaatan } \\
\text { kain perca }\end{array}$ \\
\hline
\end{tabular}

Sesuai dengan penjadwalan diatas, program dilakukan pada hari minggu di kediaman Kepala Dusun Turi Pukul 08.00 WIB pelatihan pemanfaatan kain perca dilakukan dengan membagikan kain perca, benang, jarum jahit, lem dan pernak pernik kepada undangan yang hadir. Setelah itu baru para mahasiswa memerikan contoh kepada undangan yang hadir pada waktu itu.

Masyarakat yang hadir cukup antusias dalam mengikuti pelatihan pemanfaatan kain perca. Masyarakat menirukan apa yang dicontohkan oleh mahasiswa, kebanyakan masyarakat belum pernah membikin bross dari kain perca. Namun berkat pelatihan dari rekan mahasiswa masyarakat dapat membuat bross dari kain perca bahkan salah satu masyarakat membuat bross dengan bagus sehingga panitia memberikan hadiah sebagai reward agar merangsang masyarakat untuk menekuni pemanfaatan kain perca untuk di jual, sehingga dapat meningkatkan taraf ekonomi masyarakat.
Alat dan Bahan :
1. Gunting
2. Benang dan Jarum Jahit
3. Jarum Pentul
4. Peniti Bros
5. Kain Perca
6. Lem
7. Penggaris
8. Kancing baju
Langkah-langkah cara membuat Playdough :
1. Menyiapkan alat dan bahan
2. Masukan benang kedalam jarum
3. Siapkan kain yang hendak dijahit
4. Bentuk motif yang akan dibuat
5. Ketika motif kegiatan sudah dibuat maka mulailah menjahit.
6. Setelah terjahit berikan asesoris atau pernak-pernik untuk memperindah bros yang sudah di jahit

7. Setelah itu berikan lem untuk merekatkan peniti bros.

\section{Uraian penggunaan dana Pelatihan} Pemanfaatan Kain Perca:

\begin{tabular}{cll}
\hline No. & Nama Barang & \multicolumn{1}{c}{ Harga } \\
\hline 1. & Kain perca & $\operatorname{Rp} 17.000 \times 1 \mathrm{~kg} @$ \\
2. & gunting & $\mathrm{Rp} \mathrm{7.000 \times 10@}$ \\
3. jarum & $\mathrm{Rp} 5.000 \times 3 @$ \\
4. benang & $\operatorname{Rp} 5.000 \times 3 @$ \\
Jumlah & $\mathrm{Rp} 117.000,00$ \\
\hline
\end{tabular}

\section{PENUTUP}

a. Simpulan

Pada dasarnya pelatihan ini dilaksanakan atas dasar keinginan team pengabdian UNIPA 2017 untuk memberdayakan masyarakat melalui pelatihan pemanfaatan kain perca.Tujuanya adalah untuk memberi keterampilan kepada masyarakat desa Cangkring turi sehingga dengan keterampilan tersebut dapat dikembangkan dan menghasilkan pemasukan keuangan warga desa CangkringTuri.

Antusias masyarakat desa Cangkring Turi cukup baik.Hal ini sebuah respon positif bahwa pada dasarnya masyarakat desa Cangkring Turi senang untuk belajar.Jadi kegiatan pelatihan 
pemanfaatan kain perca berjalan cukup baik.Setalah dievaluasi banyak masyarakat desa Cangkring Turi meneruskan atau mengembangkan pembuatan bross dengan kain perca. Semoga apa yang sudah dilakukan team pengabdian UNIPA 2017 mampu meningkatkan ekonomi masyarakat. Sehingga tujuan dari kegiatan tersebut dapat tercapai.

\section{b. Saran}

1) Hendaknya pemerintah desa memberi fasilitas untuk meberikan mentor kepada masyarakat sehubungan dengan pembuatan bross dengan bahan dasar kain perca

2) Untuk masyarakat desa Cangkring Turi unutk tekun mengasah keterampilan dalam membuat bross dan terus menginovasi pembuatan bross dari kain perca, agar produk bross dari desa Cangkring Turi dapat dikenal didalam dan diluar negri

3) Untuk masyarakat desa Cangkring Turi yang sudah bisa membikin bross dari kain perca untuk tidak pelit ilmu dan membagikan ilmunya kepada warga-warga yang lain.

\section{DAFTAR PUSTAKA}

Suryani. 2014. Meningkatkan Minat untuk memanfaatkan barang bekas menjadi nilai ekonomis. Jakarta: Rineka Cipta

Shofyatun A. Rahman. 2010.Pemanfaatan Kain Perca. Palu: Tadulako University Press.

(http://databermanfaat.blogspot.co.id/2014/0 6/berbagi-makalah-bertemakan-kainperca.html) di akses tanggal 08 Maret 2017 pukul 12.00 WIB

Keputusan Menteri Keuangan Nomor 316/KMK 016/1994 tanggal 27 Juni 1994

Rudjito. 2010. Pengembangan UMKM di Indonesia. Jakarta:Rineka Cipta 